\title{
Arbor
}

\section{Las amenazas globales del siglo XXI}

\section{Juan Avilés Farré}

Arbor CLXXX, 709 (Enero 2005), 247-268 pp.

El mundo de comienzos del siglo XXI se caracteriza por el desarrollos de nuevas amenazas de carácter transnacional, a menudo protagonizadas por agentes no estatales, que ponen en cuestión los límites tradicionales entre la seguridad exterior y la seguridad interior, al tiempo que crece la conciencia de la estrecha interrelación entre los problemas económicos, sociales $y$ medioambientales $y$ los problemas de seguridad. Las principales amenazas pueden agruparse en cinco áreas: pobreza, enfermedades infecciosas y deterioro medioambiental; conflictos armados; proliferación de armas nucleares, biológicas, químicas y radiológicas; terrorismo; y delincuencia organizada transnacional. Esta nueva problemática es analizada en este artículo a través de tres ejemplos: las implicaciones para la seguridad de los flujos migratorios transnacionales; la proliferación de las armas nucleares, biológicas, químicas y radiológicas y su posible uso terrorista; y el auge de la delincuencia organizada transnacional y del narcotráfico.

Si la misión fundamental de los servicios de inteligencia es analizar las amenazas a las que un país se enfrenta, esta tarea se va haciendo cada vez más compleja. En primer lugar, la profundización de la democracia implica que la seguridad de los ciudadanos adquiere tanta importancia como la seguridad del Estado. En segundo lugar, las amenazas más graves no vienen ya sólo de otros estados, sino también de agentes 
no estatales, como el terrorismo o la delincuencia organizada transnacional. En tercer lugar, se ha producido una globalización de las amenazas, por lo cual la seguridad de los distintos países del mundo está más interrelacionada que nunca. Y finalmente cada vez somos más conscientes de que la seguridad es resultado de la interacción de un gran número de factores, incluidos los demográficos, sociales y medioambientales.

En estas nuevas circunstancias, la tradicional distinción entre los dos ámbitos de la seguridad, el exterior y el interior, está perdiendo relevancia, lo que pone en cuestión principios como la rígida diferenciación entre las misiones de las fuerzas armadas y de las fuerzas de seguridad ${ }^{1}$. El proceso de globalización está potenciando las amenazas transnacionales, es decir las amenazas a la seguridad interior procedentes de agentes no estatales que actúan a través de las fronteras internacionales. Un estudio del Strategic Studies Institute de los Estados Unidos, publicado poco antes del 11-S, destacaba ya cómo este tipo de amenazas, especialmente el terrorismo internacional, los ataques cibernéticos a las infraestructuras nacionales y la delincuencia organizada transnacional, plantean la necesidad de combinar las estrategias respectivas de las instituciones de defensa y las de justicia e interior, aunque ello no resulta en absoluto fácil, sobre todo porque es necesario evitar que resulte dañado el fundamental equilibrio entre libertad y seguridad ${ }^{2}$.

Un reciente informe presentado al secretario general de las Naciones Unidas por un panel de expertos, encabezado por el ex primer ministro tailandés Anand Panyarachun, agrupa en cinco áreas las principales amenazas a las que se enfrenta el mundo actual ${ }^{3}$. La primera se refiere a la pobreza, las enfermedades infecciosas y el deterioro medioambiental, la segunda a los conflictos armados, tanto interestatales como internos, la tercera a la proliferación de las armas nucleares, biológicas, químicas y radiológicas, la cuarta al terrorismo y la quinta a la delincuencia organizada transnacional. Esto supone que bajo un mismo concepto general de amenazas se engloban problemas típicos de la seguridad exterior (conflictos interestatales y proliferación de armamento), otros que solían ser abordados desde la perspectiva de la seguridad interior (terrorismo y de-

1 J. AVILÉs, «Por un concepto amplio de seguridad», en Monografías del CESEDEN 55 (2002).

2 C.W. PUMPhReY, Transnational threats: blending law enforcement and military strategies. Carlisle, Strategic Studies Institute, 2000, 1-10.

3 UNITED NATIONS, A more secure world: our shared responsibility, en www.un.org (2004). 
lincuencia) y otros correspondientes al terreno de la política económica y social (pobreza, infecciones, medio ambiente). Una amalgama que hace unos años podía resultar extraña, pero que responde a un planteamiento muy común en los estudios más recientes sobre el tema. Estamos muy lejos de la concepción decimonónica de la seguridad, que se limitaba a la política de orden público en el plano interior y a la política de defensa en el exterior, ya que, desde el final de la guerra fría, los estudiosos han enfatizado la importancia de las amenazas no tradicionales, algunas de las cuales, como las relacionadas con la degradación del medio ambiente, el bienestar económico o las migraciones, no han sido abordadas desde la perspectiva de la seguridad hasta muy recientemente.

Resulta fundamental tener presente la interrelación entre estos distintos tipos de amenazas. Numerosos estudios han puesto por ejemplo de manifiesto la influencia de factores económicos y demográficos en el surgimiento de conflictos internos. Basándose en modelos econométricos del Banco Mundial, Macartan Humphreys, de la Universidad de Harvard, estima la probabilidad de que en los próximos cinco años surja una guerra civil en un país es tanto mayor cuanto menor es su PIB por habitante, situándose en un $15 \%$ en el caso de un país con menos de 250 dólares, y en menos del 1\% en el caso de un país con más de 5000 dólares ${ }^{4}$.

Por su parte, los expertos del Population Action Group han destacado la influencia que en el estallido de conflictos internos tiene el fenómeno de la hipertrofia juvenil (youth bulge), es decir el porcentaje inusualmente elevado de jóvenes entre de 15 a 29 años respecto al conjunto de la población adulta, que se da los países en desarrollo; es decir en los países que se encuentren en la fase intermedia de la transición demográfica, en los que la fuerte caída de las tasas de mortalidad no ha sido todavía compensada por una caída semejante de la natalidad. De acuerdo con sus cálculos, en la última década del siglo XX la probabilidad de que surgiera un conflicto interno (concepto en el que se incluyen tanto las guerras civiles como otros conflictos de menor intensidad) era del $33 \%$ en los países con más de un $40 \%$ de jóvenes adultos y del $11 \%$ en los países con menos del $30 \% 5$.

El papel que los problemas ecológicos pueden jugar como factores de conflicto, internacional y sobre todo interno, viene siendo analizado desde hace años por Thomas Homer-Dixon. Los problemas más importantes

\footnotetext{
${ }^{4}$ M. HUMPHEYS, Economics and violent conflict, en www.preventconflict.org (2003).

5 R.P. Cincotta, R. Engelman y D. Anastasion, The security demograph: Population andc civil conflict after the Cold War, en www.populationaction.org (2003).
} 
a este respecto son la deforestación, la degradación del suelo agrícola, el uso excesivo y la contaminación de los recursos hidráulicos y el agotamiento de los recursos pesqueros, ya que tienden a generar efectos sociales como reducción de la producción agrícola, declive económico, desplazamiento de población y deterioro de las instituciones y las pautas de relación social, que a su vez pueden provocar conflictos tales como disputas por recursos entre países, enfrentamientos étnicos e insurrecciones $^{6}$.

Reflexiones semejantes se podrían hacer sobre la influencia del SIDA en las difíciles perspectivas económicas, sociales e incluso de seguridad a las que se enfrenta el África subsahariana, la región del globo más devastada por la epidemia. También es evidente la relación entre delincuencia organizada y conflicto interno en ciertos países, muy especialmente en el caso de Colombia, donde los ingresos del narcotráfico son la principal fuente de financiación tanto de las FARC como de las Autodefensas.

Podría objetarse, sin embargo, que los distintos tipos de amenazas a las que hasta ahora hemos hecho alusión se dan casi exclusivamente en los países en desarrollo. Es evidente que los países más desarrollados han logrado reducir considerablemente los niveles de pobreza, mantienen bajo control las enfermedades infecciosas y han reducido también los impactos negativos de su actividad económica sobre el medio ambiente local. También es obvio que no ha habido guerras entre países muy desarrollados desde 1945 y que en tales países no se generan ni guerras civiles ni surgen grupos terroristas importantes (los que surgieron a finales de los años sesenta en Europa occidental han abandonado las armas o están en pleno declive). Tampoco hay países muy desarrollados que pretendan incorporarse clandestinamente al reducido grupo de los que ya poseen armas nucleares. Y finalmente puede afirmarse que, si bien la delincuencia organizada es un mal universal, son muy reducidos las áreas del mundo desarrollado en que esta ha llegado a adquirir un verdadero poder económico y una real influencia política (aunque es cierto que esto ocurre en algunos lugares de Italia y quizá de otros países avanzados). En conjunto podría decirse que estamos ante un conjunto de males que, como la malaria y el paludismo, sólo tienen una incidencia significativa en los trópicos. Si así fuera, los países desarrollados sólo tendrían que

6 T. HOMER-DixON, «On the threshold: environmental changes as causes of acute conflict», en International Security 16 (1991). 
preocuparse de evitar eventuales contagios, y sólo por motivos altruistas deberían esforzarse en apoyar a los países afectados.

Pero en la era de la globalización esto no es así. Los problemas que surgen en un país terminan afectando a la seguridad de otros muy lejanos y son muchos los riesgos que sólo pueden ser abordados eficientemente desde la perspectiva de la cooperación internacional. Las tres cuestiones que abordaremos a continuación ejemplifican estos efectos de la globalización sobre los problemas de seguridad en el siglo XXI. Se trata de de las migraciones internacionales, de la proliferación de armas NBQR y del avance de la delincuencia organizada transnacional.

\section{Pobreza, migraciones y seguridad}

$\mathrm{Al}$ analizar la cuestión de las migraciones, la primera consideración que debe hacerse es que se trata de un fenómeno natural, casi constante en la historia humana y en términos generales muy positivo, aunque puede generar problemas de seguridad. Desde la perspectiva de este artículo, nos interesan los que pueden surgir de los flujos migratorios que se dirigen de los países en desarrollo a los países desarrollados.

En principio, deberíamos esperar que la migración se produjera básicamente en función de la diferencia de salarios entre el país receptor y el país emisor. Sin embargo, puesto que la migración internacional exige a menudo un gasto relativamente importante, la extrema pobreza la dificulta. Por ello, aunque el desarrollo económico del país emisor conduce a largo plazo a una disminución de la tendencia migratoria (al reducirse la diferencia salarial respecto a los países receptores), a corto plazo puede ocurrir lo contrario, porque la creciente prosperidad permite a los individuos y las familias acumular unos ahorros con los que financiar su migración.

Junto a los factores económicos, se deben tener en cuenta los demográficos y especialmente la hipertrofia de jóvenes en los países en desarrollo, que se traduce en una desesperante falta de salidas profesionales. Esa hipertrofia juvenil es a su vez resultado de las elevadas tasas de fertilidad imperantes entre quince y treinta años atrás. Ahora bien, en términos generales existe en el mundo actual una correlación inversa entre desarrollo económico y fertilidad, debido a lo cual la tasa de natalidad es más elevada en los países menos desarrollados. Esto tiende a producir unos desequilibrios (escasez de trabajadores en los países desarrollados, escasez de puestos de trabajo en los países en desarrollo) que seguirán 
generando en las próximas décadas unas fuertísimas presiones migratorias. En la mayoría de los países en desarrollo las tasas de fertilidad se están reduciendo, por lo que el problema de la hipertrofia juvenil se irá reduciendo. Más difícil es prever la evolución demográfica de los países desarrollados, la gran mayoría de los cuales tienen hoy una fertilidad por debajo de la tasa de reemplazo de dos hijos por mujer, con lo cual se tiende a producir una peligrosa reducción proporcional de la población en edad laboral, que hoy por hoy resulta difícil de paliar sin recurrir a trabajadores inmigrantes.

$\mathrm{Al}$ analizar los riesgos de seguridad que genera en un país la llegada de un considerable flujo de inmigrantes hay que evitar dos errores opuestos, el de considerar infundado cualquier temor que en este sentido puedan manifestar sectores de la opinión pública, y el de considerar que todo temor tiene fundamento, con el resultado de justificar todos los prejuicios xenófobos. Con la dificultad adicional de que, en éste como en otros muchos casos, la percepción pública del problema es parte del problema. Es decir que una reacción xenófoba resulta preocupante, independientemente de que se base en motivos reales o imaginarios.

De acuerdo con un estudio pionero en la consideración de las migraciones desde la perspectiva de la seguridad existen cuatro motivos por los que una comunidad inmigrante puede crear un problema de dicha índole al país receptor ${ }^{7}$.

a) La actividad de los inmigrantes contra el gobierno de su país de origen puede representar un factor de tensión internacional. Es el caso bastante frecuente del grupo armado que emplea el territorio de un país extranjero y recurre al apoyo de sus compatriotas en él asentados para impulsar acciones contra el gobierno de su propio país.

b) Grupos de inmigrantes pueden representar una amenaza directa para la seguridad del país receptor. Esta amenaza puede venir de grupos terroristas o de organizaciones delictivas comunes $(\mathrm{y}$ en algún caso la distinción entre un tipo y otro no es nítida, porque organizaciones armadas de finalidad política cometen a menudo delitos comunes, como atracos o tráfico de drogas, para financiarse).

c) Pueden producirse conflictos xenófobos si ciertas comunidades inmigrantes son percibidas como una amenaza para el bienestar so-

7 M. WEINER, «Security, stability and international migration», en International Security 17 (1992), 197-209. 
cial del país receptor. Es frecuente que los inmigrantes provoquen resentimiento debido a la percepción de que ocasionan un incremento de la delincuencia, quitan puestos de trabajo, conducen a un descenso de los salarios, o restan recursos sociales a la población local en temas como sanidad, educación o seguridad social.

d) Por último debe tenerse presente la posibilidad de que la inmigración sea percibida como amenaza a la identidad cultural del país receptor. La xenofobia puede surgir directamente de la percepción de que los recién llegados ponen en cuestión la homogeneidad lingüística, religiosa o de costumbres de la población local. Y debe considerarse que la identidad cultural parece representar a la vez una necesidad básica de las personas y un factor potencialmente generador de violencia, en forma de nacionalismo excluyente o fundamentalismo religioso. Esa deriva violenta del sentimiento de identidad surge de una percepción, fundada o no, de la misma se halla amenazada. En palabras de un escritor libanés y francés que ha dedicado un lúcido ensayo a este tema: «lo que por comodidad llamamos "locura asesina" es esa propensión de nuestros semejantes a transformarse en asesinos cuando sienten que su 'tribu' está amenazada» ${ }^{8}$.

En el pasado, tanto en Estados Unidos como, en menor medida, en Francia y otros países europeos, la pauta habitual era que los inmigrantes se adaptaran a la lengua, a las costumbres y a los valores del país re ceptor, con lo cual terminaban siendo aceptados e integrados, al menos en la segunda generación, pero no está tan claro que vaya a ocurrir lo mismo con los flujos de inmigrantes que están llegando últimamente. Hoy en día la distancia cultural entre el país de origen y el de acogida es a menudo mayor de lo que era en el pasado, la legitimidad de forzar a los inmigrantes a abandonar su propia cultura se halla en entredicho, y la facilidad de las comunicaciones y los viajes permite que los inmigrantes mantengan una estrecha relación con sus países de origen, que refuerza su identidad particular. Se plantea por todo ello la posibilidad de que se

\footnotetext{
8 A. MaAlouf, Identidades asesinas. Madrid, Alianza Editorial, 1999.

9 M.O. Heisler y Z. LAYTON-Henry, Z. «Migration and the links between social and societal security». En O. Waever, B. Buzan, M. Kelstrup y O. Lemaitre, Identity, migration and the new security agenda in Europe. Londres, Pinter, 1993, 160-161. Sobre el caso español véase: IUISI, Inmigración y seguridad. Madrid, Instituto Universitario de Seguridad Interior, 2004.
} 
consolide la existencia de comunidades transnacionales, es decir comunidades que se integran en los países receptores sin perder sus vínculos con los países de origen, creando lazos que transcienden las fronteras geográficas, políticas y culturales.

En el caso de España, el debate sobre la inmigración ha adquirido un considerable relieve en los últimos años. Ello no es sorprendente, si se tiene en cuenta que la proporción de residentes extranjeros en España se ha triplicado en la últiima década, aunque siga siendo menor que en otros países europeos con más tradición inmigratoria.. Por otra parte, la inmigración ha permitido poner fin al descenso constante en el número de nacimientos que España venía experimentando desde 1976, que ha dado paso a una recuperación desde $1999^{10}$.

La sociedad española, como la europea en general, va a ser pues cada vez más multiétnica. Conviene por tanto plantearse cual es la actitud de los españoles hacia la inmigración y la convivencia interétnica. De acuerdo con las encuestas, parece ser relativamente favorable. Un estudio del CIS de febrero de 2000 mostró que el $43 \%$ de los españoles consideraba la inmigración como positiva para los países desarrollados, frente a un $24 \%$ que la consideraban negativa. Esa percepción favorable la compartían los encuestados de 14 de las 17 comunidades autónomas españolas, los de todos los niveles de estudios (en mayor medida cuanto mayor era dicho nivel) y los de todos los segmentos de autoposicionamiento ideológico, excepto los de extrema derecha. En la misma encuesta se percibía sin embargo un motivo de preocupación: el 51\% de los encuestados estaba de acuerdo con que el aumento de los emigrantes favorecía el incremento de la delincuencia, frente a un $35 \%$ que estaba en desacuerdo. Esta preocupación era compartida por los encuestados de todos los niveles de estudios, excepto los universitarios, y los de todos los segmentos de autoposicionamiento ideológico, excepto los de extrema izquierda ${ }^{11}$. Una encuesta más reciente del CIS, el barómetro de junio de 2002, dio resultados parecidos. Y de acuerdo con una encuesta realizada en enero de 2003 por el Instituto Opina, los españoles perciben a la inmigración como el principal factor en el incremento de la inseguridad ciudadana, siendo el $57 \%$ los que lo consideran un factor importante ${ }^{12}$.

10 R. SANDELL, «La población europea: las últimas tendencias y sus implicaciones políticas», en www.realinstitutoelcano.org (2003).

11 CENTRO DE ANÁlisis y PRosPeCtiva DE LA GuARdia CIVIL, «Inmigración y seguridad: tendencias en el año 2000", en www.guardiacivil.org (2001).

${ }^{12}$ El País, 3/2/2003. 
Los propios inmigrantes no comunitarios parecen tener una buena opinión acerca de la actitud de los españoles hacia ellos. De acuerdo con una encuesta publicada por el IMSERSO, un $44 \%$ de ellos opinan que los españoles son menos racistas que los demás europeos, un $34 \%$ que son igual de racistas y sólo el $9 \%$ que son más racistas. Pero al mismo tiempo un $44 \%$ se sentía discriminado en el trabajo o al pedir trabajo, discriminación que no percibían un $52 \%$ de ellos ${ }^{13}$.

Por otra parte, los estudios cualitativos mediante grupos de discusión realizados en lugares con una alta proporción de inmigrantes muestran una reticencia por parte de la población española. En ello influyen diversos motivos, como la percepción de que los espacios públicos están siendo ocupados por gentes ajenas, de que los inmigrantes compiten con el pequeño comercio local y hacen bajar los salarios de los trabajadores, de que "no se integran», es decir que mantienen sus propias costumbres y formas de vida, y de que acceden a servicios sociales, como la enseñanza, que pagan los españoles ${ }^{14}$. Pero uno de los principales es el referido a la delincuencia. Un estudio muy reciente realizado en diferentes barrios y pueblos de Barcelona muestra esas dificultades de convivencia, que se dan especialmente con los inmigrantes marroquíes, debido sobre todo a la mala imagen que resulta de la pequeña delincuencia protagonizada por los adolescentes de esa nacionalidad ${ }^{15}$.

En todo esto influyen desde percepciones puramente subjetivas hasta el discurso de los políticos y de los medios de comunicación. Conviene por tanto tratar de averiguar si es cierto que la llegada de extranjeros está teniendo una incidencia en las tasas de delincuencia. El indicio más claro de que así es se encuentra en las detenciones de extranjeros por presunto delito, cuyo número ha aumentado mucho en los últimos años. Puesto que las detenciones de españoles ha tendido a descender levemente, el porcentaje de detenciones de extranjeros respecto al total se ha incrementado notablemente: era del 14,9 en 1998, 16,5 en 1999, 21,6 en 2000 y 26,6 en 2001 . Dicho de otra manera, si en 1998 era extranjero uno de cada siete detenidos, en 2001 lo era uno de cada cuatro ${ }^{16}$.

13 J. DíEz Nicolás y M.J. Ramírez Lafita, M.J. (2001), La voz de los inmigrantes. Madrid IMSERSO, 2001.

${ }_{14}$ V. PÉrez Díaz, B. Álvarez-Miranda, y C. GonzÁlez-EnRíquez (2001), España ante la inmigración. Barcelona, Fundación La Caixa.

15 C. GonZÁlez EnRíqueZ, "La convivencia con los inmigrantes en Barcelona», en www.lafactoriaweb.com (2002).

16 J. AvILÉs, «Inmigración y delincuencia», en www.realinstitutoelcano.org (2003). 
Aparentemente los extranjeros, que representaban un 3\% de la población, o todo lo más un $4 \%$ si tenemos en cuenta a los inmigrantes irregulares, serían pues responsables de aproximadamente una cuarta parte de los delitos cometidos en el año 2001. La desproporción es demasiado grande como para que pudiera atribuirse a una presunta tendencia a de tener preferentemente a sospechosos extranjeros. Pero tampoco se puede caer en la interpretación simplista que atribuye mecánicamente el incremento de la delincuencia al incremento de la inmigración. La explicación ha de buscarse en dos fenómenos que son distintos entre sí, pero cuyo efecto respectivo es muy difícil de diferenciar, por un lado el auge de la delincuencia organizada transnacional, que abordaremos más adelante, y por otro lado los factores criminógenos que inciden en las poblaciones inmigrantes, que examinamos a continuación.

Los estudios realizados en distintos países demuestran que no hay una relación constante entre inmigración y delincuencia, es decir que no se puede afirmar que las poblaciones inmigradas tengan siempre una propensión a la delincuencia ni mayor, ni igual, ni menor que las autóctonas. Todo depende del lugar y del período que se considere. La comisión Wickersman, que estudió minuciosamente el tema en Estados Unidos en los años treinta, llegó a la conclusión de que «en proporción a sus respectivos efectivos numéricos, las personas nacidas en el extranjero cometen delitos menos frecuentemente que los autóctonos». Ese mismo resultado se obtuvo en Alemania, Bélgica y Suiza en los años sesenta, pero los estudios más recientes realizados en Europa occidental muestran que en los últimos años los inmigrantes presentan una tasa de delincuencia mayor que la de los autóctonos ${ }^{17}$. Esto último pudiera explicarse mediante dos teorías básicas de la criminología, la teoría de la privación relativa y la teoría del control social. De acuerdo con la primera, una persona puede verse empujada a la delincuencia por la frustración que le genera el contraste entre sus condiciones de vida y sus aspiraciones. Esta propensión a la delincuencia no respondería directamente a la privación objetiva, es decir a la pobreza en sí misma, sino que es necesario tener también en cuenta el factor subjetivo de las aspiraciones del individuo. Es fácil entender que el inmigrante, que se ha decidido a dar el gran paso de abandonar su país de origen en espera de incorporarse a una sociedad que supone mucho más rica y que de hecho puede constatar que lo es, sufra una frustración al advertir que su nivel de vida queda muy por debajo del ha-

17 M. BARBAGLI, Immigrazione e reati in Italia. Bolonia, Il Mulino, 2002 , 167-186. 
bitual en el país donde se ha instalado. Y esta teoría ayuda también a comprender el hecho, frecuentemente constatado, de que los inmigrantes de segunda generación, es decir los hijos de padres inmigrantes, presenten una tasa de delincuencia más alta que los de primera generación. En efecto, estos últimos tienen presentes las condiciones de su país de origen y por tanto pueden sentir que han prosperado, aunque se encuentren en una situación desfavorecida respecto a los autóctonos del país de acogida. Para sus hijos, en cambio, las condiciones del país de origen ya no son relevantes. Ellos aspiran a más y por tanto, a igualdad de condiciones objetivas, están más expuestos a la frustración.

Se observa sin embargo que en distintos países se manifiestan marcadas diferencias en las tasas de delincuencia de grupos étnicos de nivel social similar. En Gran Bretaña, por ejemplo, los afrocaribeños presentan una tasa de delincuencia superior a de la población autóctona, mientras que las de indios, pakistaníes y bangladeshis son inferiores, sin que ello se pueda explicar por sus niveles de renta, ya que los bangladeshis, en particular, son más pobres que los afrocaribeños. Y en los Países Bajos las condiciones de vida de turcos y marroquíes son similares, pero sólo los segundos presentan elevadas tasas de delincuencia ${ }^{18}$.

Para explicar este tipo de diferencias la teoría más útil parece ser la del control social. De acuerdo con ella, una persona está tanto menos expuesta a caer en la delincuencia cuanto más integrada se encuentra en su entorno, a través de un conjunto de valores compartidos que se transmiten en el seno de la familia, la escuela, el barrio y todo el tejido asociativo que en su conjunto conforma una comunidad. En la medida en que los inmigrantes se hallan menos identificados con los valores del país de acogida, esta teoría explica que sus tasas de delincuencia tiendan a ser en general más elevadas, pero también ayuda a entender las diferentes tasas que se dan entre diferentes grupos de inmigrantes. A este respecto lo que importa es la solidez de los vínculos sociales dentro de las propias comunidades de inmigrantes. Aquellos en que los lazos familiares sean más sólidos, por ejemplo, presentarán tasas de delincuencia menores, de donde se deduce la importancia de fomentar la reagrupación familiar.

Los atentados del 11-M, perpetrados por inmigrantes magrebíes, han venido a subrayar dramáticamente otro aspecto crucial del problema: la

18 M. TonRY, (ed.), Ethnicity, crime and immigration: comparative and cross-national perspectives, The University of Chicago Press, 1997, 1-14. 
implicación de sectores muy minoritarios de la inmigración musulmana en el terrorismo yihadista. En ello el caso del 11-M no es excepcional. Todos los grandes atentados cometidos en los últimos años en América del Norte y Europa Occidental, con excepción del de Oklahoma City, han sido obra de grupos terroristas que reclutan en las comunidades musulmanas de Occidente o las utilizan como refugio. Esto implica que, en parte, la radicalización que conduce a la yihad terrorista se está produciendo en nuestras propias sociedades. Y no se trata necesariamente de inmigrantes recién llegados, ni de gente que se encuentre en una situación desfavorable. Un estudio sobre los 212 presuntos terroristas yihadistas de los que consta que han sido detenidos o han muerto en Europa Occidental y Norteamérica entre 1993 y 2003 muestra que sólo el 16\% eran inmigrantes ilegales, y entre éstos no se hallaba ninguno de los líderes. Por el contrario el 8\% eran inmigrantes de segunda generación, es decir nacidos en el país de acogida, y otros tantos eran conversos al Is$\operatorname{lam}^{19}$. Por desgracia parece que la doctrina terrorista del salafismo yihadista resulta atractiva para cierto número de musulmanes de Occidente, ya sean estudiantes venidos de países árabes, inmigrantes llegados en busca de trabajo, jóvenes de origen árabe o pakistaní nacidos en Francia o Inglaterra, o incluso conversos. Se trata de una fe sencilla, propagada a través de predicadores y también a través de cintas audiovisuales y de portales digitales, que permite a jóvenes social o culturalmente desarraigados integrarse en una comunidad virtual de creyente ${ }^{20}$. No es necesario subrayar la importancia de prestar atención a este fenómeno de radicalización que puede conducir al terrorismo.

\section{La amenaza de las armas NBQR}

El número de guerras en el mundo parece estar reduciéndose en los últimos años, tras los elevados niveles alcanzados a comienzos de los noventa. Si en 1992 se contabilizaron 53 guerras en curso, en 2002 fueron solamente 31 , la cifra más baja desde $1977^{21}$. Como ha sido habitual durante toda la segunda mitad del siglo XX, casi todas estas guerras son ci-

\footnotetext{
19 R.S. LEIKEN, Bearers of Global Jihad: Inmigration and National Security after 9/11, en www.nixoncenter.org (2004).

20 O. Roy, L'Islam mondialisé. París, Seuil, 2002, 62-101.

21 United Nations, A more secure world: our shared responsibility, en www.un.org (2004), 11.
} 
viles. Existe pues la esperanza de que estemos empezando a controlar uno de los grandes males que la humanidad ha sufrido a lo largo de la historia. Pero el optimismo queda matizado por la amenaza que pudiera representar la proliferación del armamento nuclear y de las armas biológicas y químicas, así como su posible utilización por grupos terroristas.

Un eventual empleo de armamento nuclear representaría una catástrofe en términos de vidas perdidas, de daños económicos y de espiral de represalias. El sistema de control con el que cuenta la humanidad para evitarlo se basa en el Tratado de No Proliferación Nuclear de 1968, suscrito por 189 estados, y en la actuación del Organismo Internacional de la Energía Atómica (OIEA). El tratado implica el compromiso por parte de las cinco potencias nucleares entonces existentes, que coinciden con los cinco miembros permanentes del Consejo de Seguridad, de no transferir a otros estados tecnología armamentística nuclear y, por parte de los demás estados firmantes, de no tratar de producir armas nucleares. Los límites del sistema se pusieron sin embargo de manifiesto inmediatamente, ya que Israel, que aparentemente disponía de armas nucleares desde el año anterior, se negó a suscribirlo, a pesar de las presiones de Estados Unidos. El acuerdo al que al parecer llegaron el presidente Richard Nixon y la primera ministra Golda Meir en 1970, fue que los Estados Unidos no seguirían presionando acerca del tema, a cambio de que Israel mantenga un perfil nuclear bajo, evitando la realización de pruebas nucleares e incluso el simple reconocimiento de que dispone de armamento nuclear. Nadie duda, sin embargo, de que así es ${ }^{22}$.

Los otros dos estados que poseen armamento nuclear, desde 1998, son India y Pakistán, dos estados enfrentados desde hace medio siglo, que no han suscrito el tratado y no han ocultado su condición de potencias nucleares. Pero existen también estados que pudieran haber desarrollado programas de armamento nuclear a pesar de haber suscrito el tratado. El caso más inquietante es el de Corea del Norte, que ha revocado su firma, ha roto con el OIEA desde 2002 y ha avanzado mucho en su proyecto de producir armas nucleares, si es que no dispone ya de ellas. El proyecto de enriquecimiento de uranio por parte de Irán resulta también preocupante. Pero lo más grave quizá sea que durante dos décadas ha podido funcionar una red internacional de suministro de tecnología y equipo para la producción de armamento nuclear, con la participación de treinta empresas de distintos países, la mayoría de las cuales no sabían

${ }^{22}$ A. CoHen, Israel and the bomb. Columbia University Press, 1999. 
para qué estaban trabajando, coordinada por el científico pakistaní $\mathrm{Ab}$ dul Qader Khan y con clientes como Corea del Norte, Irán y Libia (país este último que ha renunciado recientemente a su programa nuclear).

En palabras de Mohamed el Baradei, director del OIEA, todo el sistema de control de la proliferación está en peligro, debido a la difusión de la tecnología nuclear, a la aparición de grupos terroristas deseosos de dotarse de armamento nuclear, o al menos radiológico, y al hecho de que un creciente número de estados se sienten inseguros frente a eventuales agre sores y desean disponer de la garantía nuclear. A ello se suma que la producción de uranio enriquecido o de plutonio sigue siendo libre, a pesar de que, una vez conseguida, un Estado dotado de una infraestructura industrial suficiente puede producir armas nucleares en el plazo de un año ${ }^{23}$. De acuerdo con el informe Panyarachun, unos cuarenta estados del mundo se hallan en condiciones de producir armas nucleares en un plazo corto de tiempo, y cabe el temos de que varios se decidieran a hacerlo en el caso de que el sistema basado en el Tratado de No Proliferación se viniera abajo. Existe también la posibilidad de que un grupo terrorista se dote de armas nucleares, de un tipo sencillo pero indudablemente letal. La existencia en el mundo de numerosos depósitos de uranio enriquecido, algunos de ellos insuficientemente incontrolados, representa un peligro considerable y en la última década se han registrado más de 200 incidentes relacionados con el tráfico de material nuclear ${ }^{24}$.

Desde el punto de vista de la amenaza terrorista, mucho más que un ataque nuclear, cuya posibilidad no se puede excluir, hay que temer un ataque radiológico. En este caso ya no es necesario recurrir al uranio enriquecido o al plutonio, sino a cualquiera de los materiales radioactivos que se usan en millones de establecimientos sanitarios o industriales alrededor del mundo. Con ellos se puede construir una «bomba sucia» (un Mecanismo de Dispersión Radiológica para ser más precisos), consistente en un explosivo convencional que disemina material radioactivo. Se trata de un arma mucho más apropiada para fines terroristas que para fines bélicos, ya que el número de víctimas que causaría en un primer momento no sería muy elevado, pues se debería tan sólo al efecto del explosivo convencional, pero en cambio tendría un impacto psicológico, y por tanto económico y político, muy considerable, al quedar contaminada

23 «Mohamed el Baradei: Irán no es una amenaza nuclear inminente», El País $12 / 12 / 2004$.

24 United NATIONs, $A$ more secure world: our shared responsibility, en www.un.org (2004), 39. 
radioactivamente toda un área en torno al lugar de la explosión. Algunos expertos opinan por ello que se debería hacer un esfuerzo por explicar al público que un eventual ataque de este tipo no tiene por qué ser realmente grave. Es uno de esos casos en los que básicamente sólo hay que tener miedo al miedo.

No se puede excluir tampoco un ataque contra una central nuclear, por el procedimiento de estrellar un avión contra ella, lo que pudiera provocar una catástrofe, como lo ha puesto de manifiesto un estudio encargado por el gobierno alemán ${ }^{25}$.

En cuanto a las armas químicas, algunas son de producción relativamente sencilla, pero no es en absoluto fácil emplearlas como verdaderas armas de destrucción masiva. De hecho, después de su empleo inicial en la Primera Guerra Mundial, su uso bélico ha sido limitado, aunque Saddam Hussein las utilizó en los años ochenta, tanto contra las tropas iraníes como contra la población civil del Kurdistán iraquî26. En cuanto a la eventualidad de su uso terrorista, se puede decir que es fácil emplearlas para matar a pocas personas, pero muy dificil hacerlo para matar a muchas. De hecho ha habido en los últimos años algunos casos de terrorismo químico, pero sólo uno ha revestido cierta gravedad. Se trata del protagonizado por la secta Aum Shinrikyo, cuyo proceso se ha celebrado recientemente en Japón. La muy escasa atención que hasta hace muy pocos años se prestaba a este tipo de amenazas se demuestra por el asombroso hecho de que aquella secta milenarista, que pretendía acelerar la llegada del apocalipsis mediante atentados masivos, pudiera montar una auténtica fábrica de armas químicas, en la que hubo en 1994 un accidente con gas mostaza que causó siete muertes, y realizar varios atentados letales con gas sarín y VX, sin que nada de ello llamara la atención de las autoridades, hasta que se produjo el atentado del 20 de marzo de 1995 en el metro de Tokyio, también con gas sarín, que mató a doce personas y provocó la hospitalización de más de mil ${ }^{27}$. Después del 11-S tales amenazas se toman con mucho mayor seriedad y en París, por ejemplo, se realizó en octubre de 2003 un ejercicio de simulación de un ataque con gas neurotóxico ${ }^{28}$.

\footnotetext{
25 «Les centrales nucléaires à la merci d'une attaque terroriste », Le Figaro, 31-122003.

${ }^{26}$ R. HARRIS y J. PAXMAN, A higher form of killing: the secret history of chemical and biological warfare. Londres, Arrow, 2002.

27 J.B. TUCKER, (ed.) Toxic terror: assessing terrorist use of chemical and biological weapons. Cambridge, Mass., Monterey Institute of International Studies, 2000.

28 «Un attentat chimique simulé pour la première fois à Paris», Le Figaro 23/10/2003.
} 
Mucho más peligroso que tales intentos pudiera resultar un ataque terrorista contra una fábrica de productos químicos, que pudiera traducirse en una catástrofe como la que se produjo accidentalmente en una planta de insecticidas en Bhopal, India, en 1984, con un balance de quizá veinte mil muertes. De acuerdo con un estudio reciente hay en Estados Unidos más de siete mil industrias químicas en las que un ataque pudiera producir más de mil muertes ${ }^{29}$.

La historia del empleo tanto bélico como terrorista de armas biológicas es bastante limitada. Ha habido varios intentos de utilizar gérmenes patógenos con fines terroristas, pero muy pocas realizaciones. A comienzos de los años noventa Aum Shinrikyo realizó varios ataques fallidos de antrax y botulismo, que pasaron por entonces desapercibidos. El primer caso en que se provocaron víctimas parece haber sido el protagonizado en 1984 por una secta hinduista, los Rajneeshes, que con el propósito de hacerse con el control de una pequeña localidad de Oregón infectaron con salmonella la comida de varios restaurantes, causando la enfermedad de 751 personas, pero ninguna muerte. El impacto que aquello tuvo en los medios de comunicación fue mínimo, por lo que el primer ataque que ha causado genuina preocupación mundial fue el envío de varias cartas con esporas de antrax, que mataron a cinco personas en Estados Unidos en octubre de 2001, cuando la opinión estaba enormemente sensibilizada por los efectos del 11-S. Aunque el caso no se ha resuelto, las sospechas apuntan hacia un científico que trabajaba en el principal centro de investigación sobre defensa bioló gica de los Estados Unidos, Fort Detrick, y sus motivaciones, en caso de que fuera realmente el responsable, permanecen oscuras.

El hecho de que algo no haya ocurrido en el pasado no implica que quepa excluirlo como amenaza futura. En principio se pueden cultivar gérmenes patógenos en un pequeño laboratorio, aunque no es tan sencillo conseguir una cepa adecuada ni mucho menos difundir los gérmenes de forma efectiva para que causen muertes masivas. Incluso Aum Shinrikyo, cuya capacidad científica y tecnológica era muy elevada, fracasó en el intento de producir armas biológicas viables. Con lo cual el mayor peligro estriba en que un Estado proporcione el arma a unos terroristas, una jugada que le resultaría menos arriesgada que suministrarles un arma nuclear, porque no resulta tan fácil identificar el origen de un germen. De hecho, un ataque bioterrorista que no fuera reivindicado pudiera ser fácilmente confundido con una epidemia natural. No es por tanto

29 «Lots of chemicals, little reaction», The New York Times, 22-9-2004. 
extraño que a partir del 11-S se le haya prestado una gran atención al tema, muy especialmente en los Estados Unidos. En mayo de 2004 el Senado aprobó el gasto de 5.600 millones de dólares en diez años para promover el desarrollo y almacenamiento de vacunas, antídotos y otros recursos sanitarios para hacer frente a un eventual ataque bioterrorista ${ }^{30}$. Sin embargo, algunos expertos consideran que, a pesar del reciente esfuerzo presupuestario, los Estados Unidos siguen estando poco preparados ante la eventualidad de un ataque bioterrorista ${ }^{31}$.

En tales circunstancias, el interés que $\mathrm{Al}$ Qaeda ha demostrado por la adquisición de armas NBQR resulta verdaderamente inquietante ${ }^{32}$.

\section{Delincuencia transnacional y tráfico de drogas}

El informe Panyaranchun acaba de definir con precisión la amenaza que representa la delincuencia transnacional organizada, que deteriora la seguridad humana y degrada la capacidad de los estados para garantizar la ley y el orden, al tiempo que contribuye a la perduración de los conflictos internos, a la proliferación de los armamentos y al terroris$\mathrm{mo}^{33}$. No se trata por tanto de una cuestión marginal, sino de un factor fundamental de inseguridad, cuyo desarrollo se ve favorecido por la globalización. No ha sido sin embargo hasta los años noventa cuando la delincuencia transnacional ha sido reconocida como un problema internacional grave. Un paso decisivo se dio en diciembre de 2000 cuando, por iniciativa de las Naciones Unidas, 124 estados firmaron en Palermo una Convención contra la Delincuencia Organizada Transnacional.

De acuerdo con el artículo 2 de la Convención, por «grupo delictivo organizado» se entenderá "un grupo estructurado de tres o más personas que exista durante cierto tiempo y que actúe concertadamente con el propósito de cometer uno o más delitos graves o delitos tipificados con arreglo a la presente Convención con miras a obtener, directa o indirectamente, un beneficio económico $u$ otro beneficio de orden material ${ }^{34}$.

\footnotetext{
30 "Senate approves bioterror provisions», The Washington Post, 20-5-2004.

31 "U.S. unprepared despite progress, experts say», The Washington Post, 8-11-2004.

32 J. SPYER, «The Al-Qa'ida network and weapons of mass destruction», en http://meria.idc.ac.il (2004).

${ }^{33}$ UnITED NATIONS, A more secure world: our shared responsibility, en www.un.org (2004).

34 El texto de la convención y de los protocolos anexos se puede consultar en www.undep.org/palermo.
} 
Una definición, por cierto, que excluye a los grupos terroristas, cuya finalidad, de acuerdo con la definición habitualmente aceptada, es intimidar a una población o forzar a un gobierno o a una organización internacional a realizar una acción o a abstenerse de realizarla.

El informe de Europol sobre delincuencia organizada correspondiente al año 2003 indicaba que habían sido detectados en la Unión Europea, constituida entonces por 15 estados, 4.000 grupos con casi 40.000 miembros. Advertía además de que la inminente ampliación de la UE ofre cería nuevas oportunidades a la delincuencia organizada. Entre los grupos autóctonos de la Europa de los 15 el informe subrayaba la importancia de los holandeses, los españoles (sobre todo en lo referente al tráfico de cannabis y cocaína), los italianos y los belgas. Entre los grupos de los países candidatos a la adhesión, destacaba a los polacos, los bálticos, los búlgaros y los rumanos. Y entre los grupos de otros países que operan en la UE destacaba a los albaneses, los procedentes de la antigua Yugoslavia, los rusos, los turcos, los nigerianos, los marroquíes, los colombianos, los chinos y los vietnamitas. Por último, dentro de la amplia variedad de delitos en los que tales grupos están implicados, subrayaba las graves implicaciones de dos de ellos, en primer lugar el tráfico de personas (incluyendo tanto la facilitación de la inmigración ilegal como la trata de seres humanos, captados mediante la violencia, la coacción, el secuestro o el engaño y explotados en la prostitución o como trabajadores ilegales) y en segundo lugar el tráfico de drogas ilegales ${ }^{35}$. En España se ha incrementado últimamente la preocupación por el asentamiento de grupos transnacionales muy violentos, especialmente en la Costa del Sol ${ }^{36}$.

No existen apenas estudios comparativos sobre los grupos delictivos transnacionales a nivel global. Uno de los más interesantes, recientemente publicado por la Oficina contra la Droga y el Delito de Naciones Unidas, consiste en un análisis de 40 grupos de 16 países y se basa a un cuestionario enviado a autoridades y expertos de dichos países ${ }^{37}$. Aunque la muestra dista mucho de ser representativa, las conclusiones del estudio ofrecen una serie de rasgos que posiblemente sean comunes al conjunto de la delincuencia organizada transnacional:

35 EUROPOL, Informe 2003 de la Unión Europea sobre la delincuencia organizada, en www.europol.eu (2003).

36 "La costa del crimen organizado», El Pais 12-12-2004.

37 OfFICE ON DRUGS AND CRIME, Results of a pilot survey of forty selected organized criminal groups in sixteen countries, en www.unodc.org (2002). 
a) Dos tercios de los grupos tienen una estructura jerárquica clásica y el resto están organizados de manera más laxa.

b) La mayoría de los grupos tienen entre 20 y 50 miembros.

c) La violencia resulta esencial en la actividad de la mayoría de los grupos.

d) Menos de un tercio de los grupos tienen una identidad étnica definida.

e) La mayoría de los grupos se concentran en una actividad delictiva principal, y sólo un tercio tiene más de tres actividades principales. La actividad más común es el tráfico de droga.

f) La mayoría de los grupos actúan en más de dos países.

g) La gran mayoría de los grupos recurren a la corrupción, de manera sistemática u ocasional.

h) Algo más de la mitad de los grupos han adquirido influencia política, a distintos niveles.

i) Casi la mitad de los grupos tienen también actividades en la economía legal.

j) La mayoría de los grupos cooperan con grupos de otros países, sobre todo para obtener mercancías ilegales, especialmente drogas.

La combinación de estas características permite definir una tipología de grupos criminales. Se observa que, en términos generales, los grupos con una jerarquía más rígida son los que más a menudo tienen una sólida cohesión basada en lazos sociales o étnicos, y son también los más violentos, los que más recurren a la corrupción, los que más invierten en la economía legal y los que más relaciones transfronterizas tienen. En resumen, los grupos más peligrosos son los que presentan las características que habitualmente se atribuyen a las «mafias» (un concepto impreciso que quizá sea mejor no utilizar). El estudio subraya sin embargo la amenaza que representa el otro tipo de grupos delictivos organizados, mucho menos visible, que se caracteriza por estructuras en red menos formales y es por tanto más difícil de combatir.

El principal negocio de la delincuencia organizada transnacional es, por supuesto, el tráfico de drogas ilegales y ello resulta tanto más grave porque el consumo de sustancias psicotrópicas representa un importante problema sanitario y social en un gran número de países. Debido a esto existe un muy amplio consenso sobre la necesidad de mantener y reforzar el sistema de control del que se ha ido dotando la humanidad, que se basa en la Convención Única sobre Estupefacientes de 1961, el Convenio sobre Sustancias Psicotrópicas de 1971 y la Convención de las Naciones Unidas contra el Tráfico Ilícito de Estupefacientes y Sustancias Psicotrópicas de 
1988, ratificadas por la casi totalidad de los estados del mundo. A pesar de ello hemos asistido durante el último medio siglo a una verdadera epidemia mundial de consumo indebido de drogas. La Oficina contra la Droga y el Delito de Naciones Unidas estima que casi el 5\% de la población mundial de más de 15 años consume droga, lo que supone 185 millones de personas, y el problema es especialmente grave entre los jóvenes. Esto no significa sin embargo que los esfuerzos de control hayan sido inútiles, porque cabe recordar que el tabaco, que es legal, es consumido por el $30 \%$ de la población mundial, con los devastadores efectos sobre la salud que se saben.

Se estima que casi 150 millones de personas consumen cannabis, unos 38 millones consumen anfetaminas y éxtasis, 15 millones consumen opiá ceos (entre ellos 9 millones heroína) y 13 millones consumen cocaína. En el conjunto del mundo el problema sanitario mayor lo constituyen los opiáceos, que provocan la mayoría de solicitudes de tratamiento, pero el consumo mundial de heroína parece estar descendiendo en los últimos años, mientras que el crecimiento más fuerte se está produciendo en el consumo de cannabis. En conjunto, las cantidades decomisadas de todo tipo de drogas han experimentado en los últimos años un fuerte aumento, que parece indicar no sólo un creciente esfuerzo para combatir el narcotráfico sino también un incremento del consumo, pero es necesario subrayar que el fuerte aumento de los años noventa ha dado paso a una estabilización a comienzos del siglo XXI. En términos de miles de millones de unidades equivalentes (es decir de dosis típicas de consumo de cualquier tipo de droga), los de comisos mundiales pasaron de 14,3 en 1985 a 26.1 en 2000 y 25,9 en 2002.

De nuevo hay que subrayar que el riesgo sanitario y social que suponen las drogas ilegales está asociado a otras amenazas, especialmente la de la delincuencia organizada. En palabras del último informe de la Oficina contra la Droga y el Delito de Naciones Unidas:

"Los vínculos entre el tráfico de drogas, la delincuencia organizada y, hasta cierto punto, la financiación del terrorismo, ocupan ahora el primer plano del panorama internacional. La reciente incorporación al sistema multilateral de un nuevo conjunto de instrumentos innovadores para luchar contra la delincuencia organizada transnacional, la trata de seres humanos, el contrabando de migrantes, el tráfico de armas de fuego y la corrupción está allanando el camino para lograr avances importantes en la lucha contra las drogas y el delito ${ }^{38}$ ).

38 Oficina Contra la Droga y El Delito, Informe mundial sobre las drogas 2004, en www.unodc.org (2004). 
Los atentados del 11-M, en cuya realización participaron delincuentes comunes que los financiaron mediante la venta de drogas, han subrayado dramáticamente este tipo de conexiones. Y España ocupa en las redes del narcotráfico una posición muy singular, como vía de entrada en Europa de la cocaína colombiana y del cannabis marroquí. De acuerdo con las estimaciones del Observatorio Español sobre Drogas, hay en España unos 200.000 consumidores problemáticos de opiáceos y cocaína, las drogas más peligrosas. El retroceso de la heroína ha conducido a que en los últimos años se haya reducido el número de muertes directamente ligadas al consumo de drogas, pero aún así se producen unas mil al año. El porcentaje de quienes han consumido cannabis en el último mes se ha duplicado entre 1995 y 2001, pasando del 3,1 al 6,5, y el de quienes han consumido cocaína se ha triplicado, pasando de 0,4 a 1,4. Y el número de detenidos por narcotráfico ha pasado de 13.967 en 1998 a 17.430 en $2002^{39}$.

Todo esto indica que España es uno de los países de la UE más afectados por el problema de la droga. De acuerdo con el último informe del Observatorio Europeo de las Drogas y la Toxicomanía, España se sitúa en el primer lugar en el consumo de cocaína por los adultos jóvenes, en tercer lugar en el consumo de cannabis y de extasis, y en el quinto lugar en el consumo de anfetaminas ${ }^{40}$.

\section{Conclusiones}

Sería un error pensar que las amenazas evocadas en este artículo deben ser afrontadas exclusivamente a través de las fuerzas de seguridad y los servicios de inteligencia. En realidad, como ha afirmado recientemente el secretario general de Naciones Unidas, Kofi Annan, nuestra mejor estrategia preventiva es apoyar el desarrollo y la mejor inversión en seguridad que puede realizar un país es destinar recursos para los objetivos del milenio, acordados en el año 2000, que pretenden una sustancial reducción de la pobreza, el hambre y otros males sociales para el año $2015^{41}$. Pero a su vez, una gran contribución al desarrollo humano se ha de hacer mediante la cooperación internacional en la lucha contra la de-

\footnotetext{
39 ObServatorio Español sobre Drogas, Informe $n^{\circ} 6$, en www.mir.es/pnd (2003).

40 Observatorio Europeo de las Drogas y las Toxicomanías, El problema de la drogodependencia en la UE y Noruega, en www.emcdda.eu.int (2004).

41 K. ANNAN, «Courage to fulfil our responsibilities», en The Economist, 12-4-2004.
} 


\section{Juan Avilés Farré}

lincuencia organizada, contra los traficantes de personas, contra el terrorismo, contra el tráfico de armamento y contra el narcotráfico. Y para todo ello es indispensable reforzar un recurso esencial: la inteligencia. 